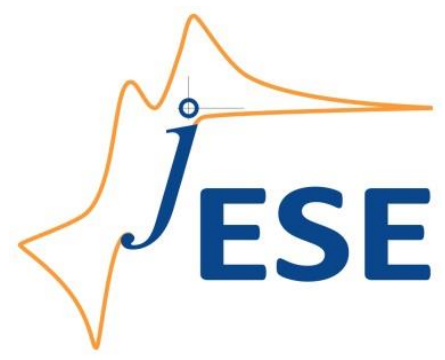

Open Access: ISSN 1847-9286

www.jESE-online.org

Original scientific paper

\title{
Enhanced voltammetric detection of paracetamol by using carbon nanotube modified electrode as an electrochemical sensor
}

\author{
Madikeri M. Charithra, Jamballi G. Manjunatha ${ }^{\bowtie}$ \\ Department of Chemistry, FMKMC College, Mangalore University Constituent College, Madikeri, \\ Karnataka, India
}

Corresponding author: ${ }^{\circledR}$ manju1853@gmail.com; Tel.: +91-08272228334

Received: August 28, 2019; Revised: November 25, 2019; Accepted: November 25, 2019

\begin{abstract}
New aspects associated with electro-catalytic activity of poly(methyl orange) modified carbon nanotube paste electrode (PMMCNTPE) towards the detection of paracetamol (PC) which is typically used worldwide as a pain reliever, were explored through implementation of cyclic voltammetry (CV) and differential pulse voltammetry (DPV) techniques. Bare carbon nanotube paste electrode (BCNTPE) was modified by methyl orange using the electropolymerizing method. The effect of $\mathrm{pH}$ and influence of potential scan rate were resolved by means of $\mathrm{CV}$ technique. It was found that under optimized experimental conditions, PMMCNTPE imparts the analytical curve for $P C$ in the concentration range of $2.0 \times 10^{-6}$ $5.0 \times 10^{-5} \mathrm{M}$ with detection limit of $3.8 \times 10^{-8} \mathrm{M}$ and limit of quantification of $1.2 \times 10^{-8} \mathrm{M}$. The proposed sensor exhibited acceptable reproducibility, admirable stability, and adequate repeatability. The interference study of $P C$ with dopamine (DA) and folic acid (FA) showed good selectivity of the designed sensor. The feasibility of the constructed electrochemical sensor to detect PC was successfully tested in some pharmaceutical formulations.
\end{abstract}

\section{Keywords}

Voltaammetric studies; electropolymerization; methyl orange; paracetamol; detection limit

\section{Introduction}

The quality of human health was vastly upgraded in last fifty years, what is predominantly due to well-developed medicines, education, and lifestyle. At the present time, an increase in daily use of pharmaceuticals to prolong life and avoid or cure various diseases, has additionally been recorded [1-2]. One of the most frequently used drugs is painkillers. Among several painkillers, paracetamol (PC) has commonly been used for fever of viral and bacterial sources and pain relief [3]. PC (acetaminophen, $\mathrm{N}$-acetyl-p-aminophenol) diminishes mild-moderate pain related with headache, migraine, toothache, backache, muscular aches, and postoperative pains [4-6]. It is the best 
substitute for patients who are sensitive to aspirin, which is also used as an analgesic [7-8]. Normally, PC does not have any harmful side effects, as it is completely metabolized into inactive metabolites that can easily be excreted via urine [9], whereas the overdoses of PC can lead to hepatic-toxicity and nephron-toxicity [10-13]. Due to its growing use, defecated PC together with PC disposal in manufacturing industrial effluents raise its presence in water source systems [14]. To control and evade these problems, the monitoring of PC becomes essential.

Drug analysis in biological systems provides valuable information in pharmacokinetic studies, and clinical diagnosis. The literature surveys revealed a number of already developed techniques for determining PC in different samples [15]. These techniques include titrimetric determination [1618], liquid chromatography-mass spectroscopy [19-20], high performance-liquid chromatography [21-22], liquid chromatography [23], capillary electrophoresis [24], chemiluminescence [25], UV-Vis spectrometry [26-27], infrared spectroscopy [28], and flow [29-30] and batch [31] injection analyses. These methods offer high sensitivity, selectivity and accuracy, but difficulties of their use such as time-consuming measurement process, highly expert technicians required for the operation, and high cost instruments, limit their extensive applications. The electrochemical approach, however, provides simple, quick, and selective analyte detection with inexpensive and durable instruments. Recently, electrochemical methods have attracted great attention because compared to traditional methods, they are simpler and more sensitive. Also, electrochemical methods offer excellent stability and repeatability and require short analytical time. The construction of novel electrochemical sensors based on carbonaceous materials such as carbon nanotubes (CNTs), graphene and graphite, has an outstanding importance in the development of electroanalytical techniques. This is due to their uncomplicated preparation, low cost, high conductivity, and biocompatibility. CNTs are one of the carbonaceous materials that have already been well inspected for the design of electrochemical sensors with fabulous physical and chemical properties, including high conductivity and large surface area [32-33].

For further enhancing of electrode properties, however, electrode surfaces should be modified. To modify CNT paste electrode (CNTPE), electro-polymerization is one of frequently used modification methods in which a certain thickness of polymer films on the electrode is obtained by regulating the number of cycles or potential values applied to an electrode. The modified CNTPE is worthy for enhancing electrode conductivity and stimulating the transfer of electrons [34-35].

The present work targets the fabrication of the electrochemical sensor based on the bare CNTPE (BCNTPE) modified with methyl orange and the fabricated PMMCNTPE sensor was implemented to the detection of PC by CV technique. The voltammetric response of PC at PMMCNTPE showed a quasi-reversible redox behavior and remarkable improvement in current sensitivity. According to reports available in the literature, BCNTPE modified with methyl orange as an electrochemical sensor was not yet utilized for the determination of PC using CV technique. The constructed sensor was successfully employed to the determination of PC, dopamine (DA) and folic acid (FA) simultaneously. The electro-oxidation mechanism of PC is shown in scheme 1.

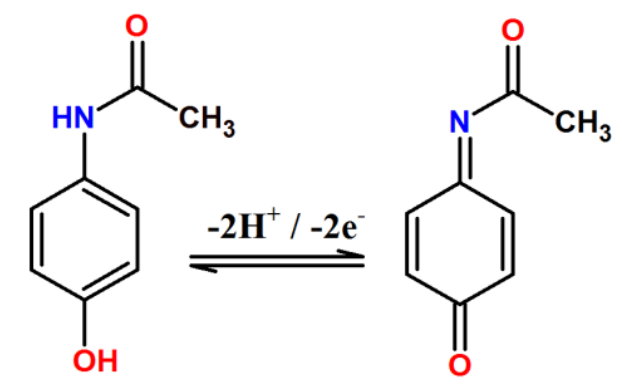

Scheme 1: Electro-oxidation mechanism of PC 


\section{Experimental}

\section{Reagents and solutions}

PC was procured from Tokyo Chemical Industry Company Ltd. (Japan). CNTs were purchased from the Sisco Research Laboratories Pvt. Ltd. Mumbai, Maharasthra (OD: 30-50 nm and length: 10-30 $\mu \mathrm{m})$. Silicone oil and methyl orange were obtained from Nice Chemicals, India. Monosodium hydrogen phosphate $\left(\mathrm{NaH}_{2} \mathrm{PO}_{4}\right)$ and disodium hydrogen phosphate $\left(\mathrm{Na}_{2} \mathrm{HPO}_{4}\right)$ were acquired from Molychem, India. All analytical grade chemicals were used without any further treatment. Stock solutions of PC $\left(25 \times 10^{-4} \mathrm{M}\right)$ and methyl orange $\left(25 \times 10^{-4} \mathrm{M}\right)$ were prepared in distilled water. PBS $(0.2 \mathrm{M})$ solutions of proper $\mathrm{pH}$ for particular experiments were prepared by mixing appropriate amounts of $0.2 \mathrm{M} \mathrm{NaH}_{2} \mathrm{PO}_{4}$ and $0.2 \mathrm{M} \mathrm{Na}_{2} \mathrm{HPO}_{4}$ and used as supporting electrolytes. All voltammetric experiments were carried out at the room temperature $\left(25 \pm 1^{\circ} \mathrm{C}\right)$.

\section{Instrumentation}

The voltammetric measurements were performed by using an electrochemical working station $\mathrm{CHI}-6038 \mathrm{E}$ ( $\mathrm{CH}$-Instruments-USA), integrated to the personal computer. The electrochemical analyzer was fitted with an electrochemical cell consisting of three-electrode compartment that comprised BCNTPE or PMMCNTPE as a working electrode, a platinum wire as an auxiliary electrode, and the standard calomel electrode (SCE) as a reference electrode. All the potential values were referred against SCE. The EQ-610 model digital pH meter was used to provide the solution with the relevant $\mathrm{pH}$ for the experiment. All peak current measurements were taken with the background current. The DST purse lab, Mangalore University, provided the FESEM characterization of the bare and modified electrodes.

\section{Fabrication of PMMCNTPE}

In the first stage of preparation of the modified electrode, BCNTPE was constructed by hand mixing of CNTs and silicone oil in the ratio 60:40 in an agate mortar and grinding with the help of pestle until a homogenous CNT paste was obtained. The resultant homogenous CNT paste was then firmly packed into the cavity of the teflon tube and smoothed on a tissue paper to obtain the uniform surface. A copper wire was introduced into the teflon tube to provide the electrical contact. Afterwards, PMMCNTPE was fabricated by electrodeposition of methyl orange on the surface of the prepared BCNTPE. Electrodeposition was carried out in $0.2 \mathrm{M} \mathrm{PBS}$ of pH 7.0 in the presence of $10^{-4}$ $\mathrm{M}$ methyl orange, for 15 continuous potential cycles between -0.6 to $1.4 \mathrm{~V}$ at a scan rate $0.1 \mathrm{~V} \mathrm{~s}^{-1}$. After electrochemical polymerization, the surface of the prepared PMMCNTPE was thoroughly washed with the distilled water and used for the further electrochemical analysis.

\section{Results and siscussion}

\section{Electrochemical polymerization of methyl orange on BCNTPE}

Methyl orange $(\mathrm{MO})$ is a redox indicator undergoing polymerization. Electrochemical polymerization of $\mathrm{MO}$ was carried out on the surface of BCNTPE between $-0.6 \mathrm{~V}$ and $1.4 \mathrm{~V}$ for 15 cycles at the scan rate $0.1 \mathrm{~V} \mathrm{~s}^{-1}$, and an adequate polymer growth was attained. Figure 1 shows cyclic voltammograms (CVs) of the electrochemical polymerization of $10^{-4} \mathrm{M} \mathrm{MO}$ in $0.2 \mathrm{M} \mathrm{PBS}$ of pH 7.0 indicating satisfactory development of the polymer on the surface of BCNTPE. Two anodic peaks and one reduction peak in CVs are related to the redox behavior of $\mathrm{MO}$. The electrochemical polymerization of $\mathrm{MO}$ has been already reported [36-38]. 


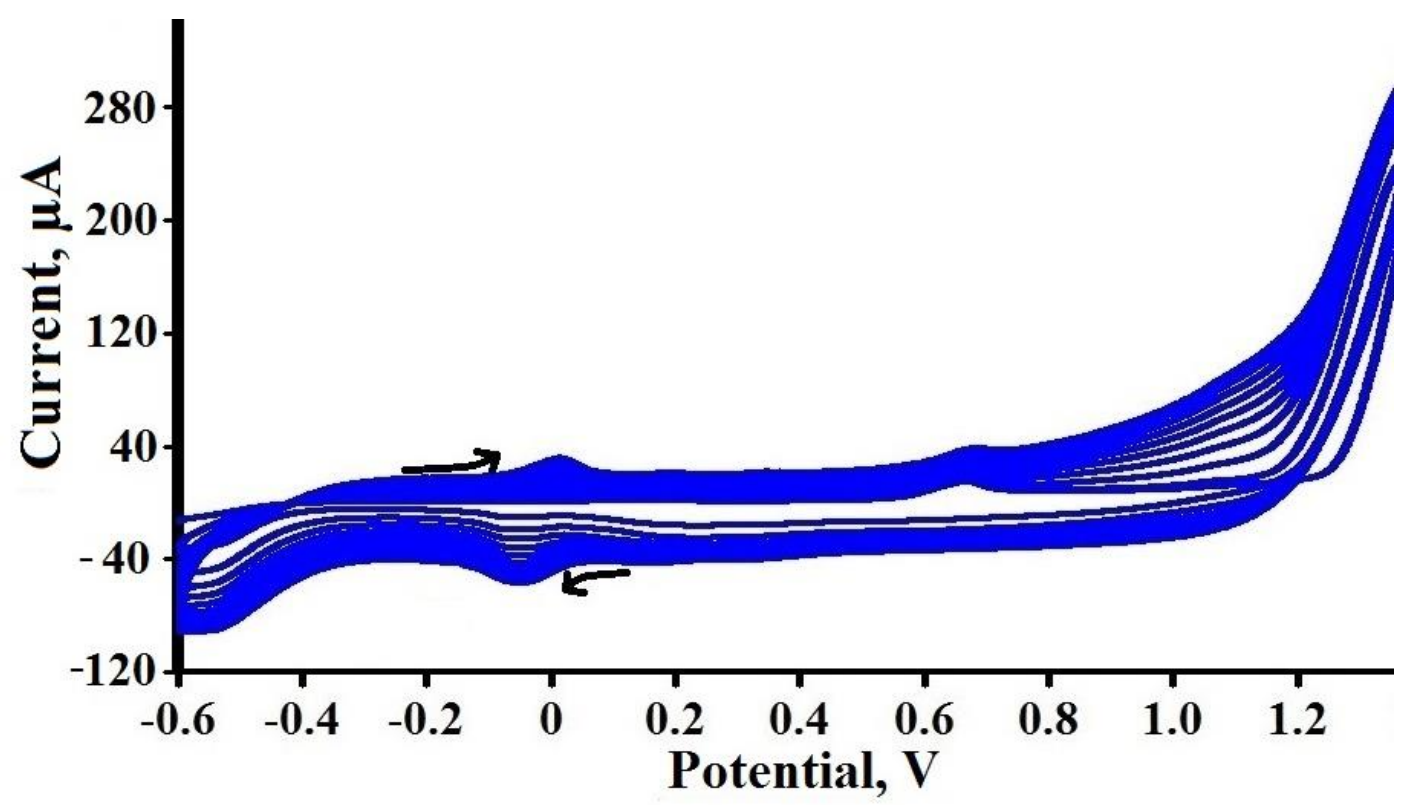

Figure 1. Electrochemical polymerization of methyl orange at BCNTPE

\section{Surface morphology characterization of BCNTPE and PMMCNTPE}

The surface morphologies of BCNTPE and PMMCNTPE were probed with FESEM. Figures 2(a) and 2(b) present FESEM images of BCNTPE and PMMCNTPE, respectively. The FESEM image of BCNTPE discloses a rough surface morphology with a tube-like CNT structure, while the smooth surface morphology in FESEM image of PMMCNTPE shows formation of uniform polymeric film of MO on the surface of BCNTPE. Therefore, by comparing FESEM images of BCNTPE and PMMCNTPE, it can clearly be seen that electrodeposition of $\mathrm{MO}$ on the surface of BCNTE was successfully achieved forming poly-MO film by electrochemical polymerization.

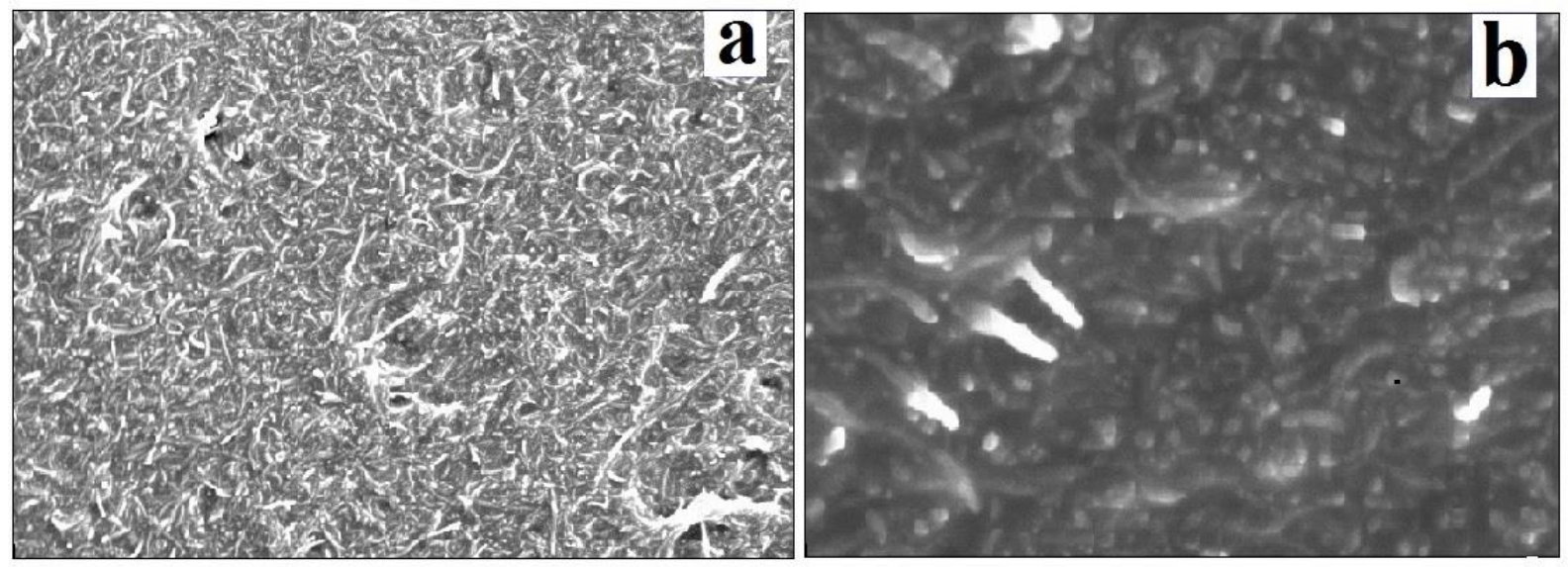

Figure 2. FESEM magnified image of (a) BCNTPE and (b) PMMCNTPE

Electrochemical behavior of PC at BCNTPE and PMMCNTPE characterized by CV technique

The electroactivity of PC compound on PMMCNTPE has been analyzed by means of CV method. Figure 3 presents cyclic voltammetric responses of $10^{-4} \mathrm{M} \mathrm{PC}$ at PMMCNTPE (dashed line) and BCNTPE (solid line) in $0.2 \mathrm{M} \mathrm{PBS}$ of $\mathrm{pH} 7.5$, recorded at the scan rate $0.1 \mathrm{~V} \mathrm{~s}^{-1}$ in the potential window $0 \mathrm{~V}$ to $0.8 \mathrm{~V}$. BCNTPE offers less significant oxidation peak with a current of $24.2 \mu \mathrm{A}$ without a reduction peak. PMMCNTPE, however, shows boosted electrocatalytic behavior towards the electro-oxidation of PC with an oxidation peak at $0.357 \mathrm{~V}$ having current value of $72.9 \mu \mathrm{A}$ and a welldefined reduction peak at $0.217 \mathrm{~V}$ with current of $41.2 \mu \mathrm{A}$, respectively. The redox peak currents of 
$\mathrm{PC}$ at PMMCNTPE are higher than the redox peak currents of PC at BCNTPE. Also, $\Delta E_{\mathrm{p}}$ is $0.14 \mathrm{~V}$, what suggests a quasi-reversible redox performance of the PC on the surface of PMMCNTPE [39]. Hence, PMMCNTPE shows a good electrochemical sensing performance towards the redox behavior of PC.

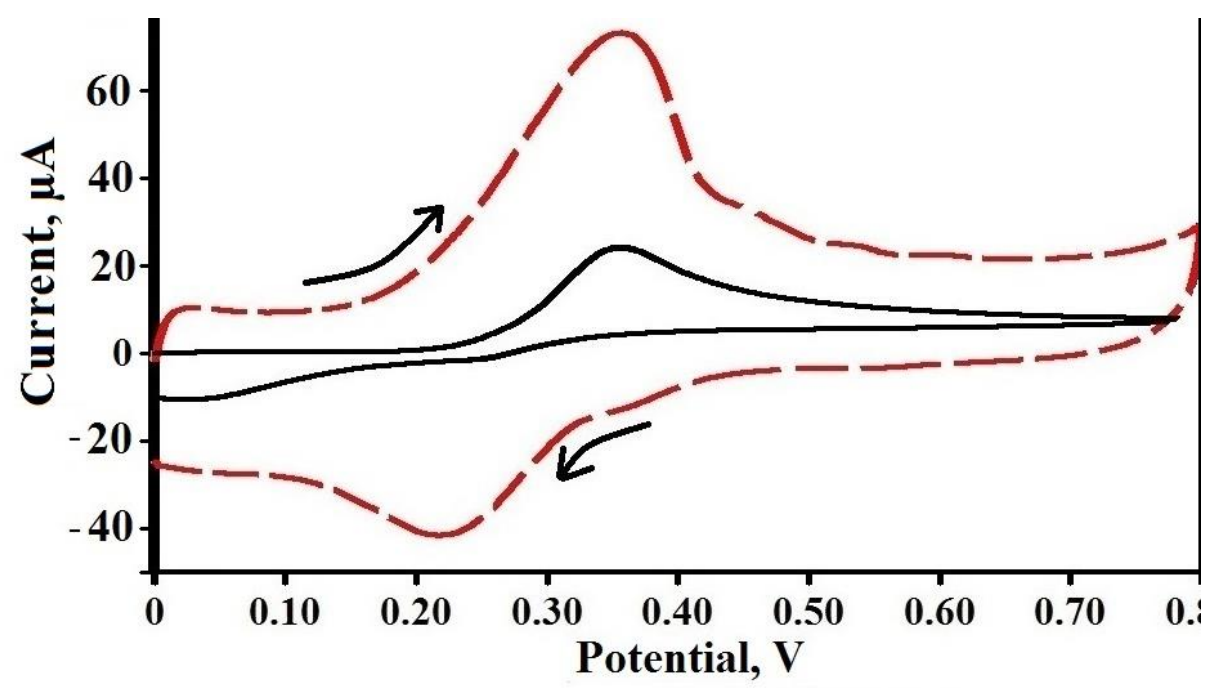

Figure 3. CVs of $P C\left(10^{-4} \mathrm{M}\right)$ at BCNTPE (solid line), and PMMCNTPE (dashed line) in $0.2 \mathrm{MPBS}$ of $\mathrm{pH} 7.5$, at the scan rate $0.1 \mathrm{Vs}^{-1}$

\section{Electrochemical response of PC on PMMCNTPE}

The electrochemical response of PC at PMMCNTPE was inspected with CV technique. Figure 4 presents CVs at PMMCNTPE without (curve a) and with (curve b) PC in 0.2 M PBS of pH 7.5. CVs were recorded at the scan rate $0.1 \mathrm{~V} \mathrm{~s}^{-1}$ and potential scanned between $0 \mathrm{~V}$ to $0.8 \mathrm{~V}$. In the presence of $\mathrm{PC}$, oxidation peak appeared at $0.357 \mathrm{~V}$ with a current of $72.9 \mu \mathrm{A}$ while without $\mathrm{PC}$ in the solution, redox peaks were not observed. Therefore, the above result suggests that the analyte PC could be detected by PMMCNTPE by utilizing CV method.

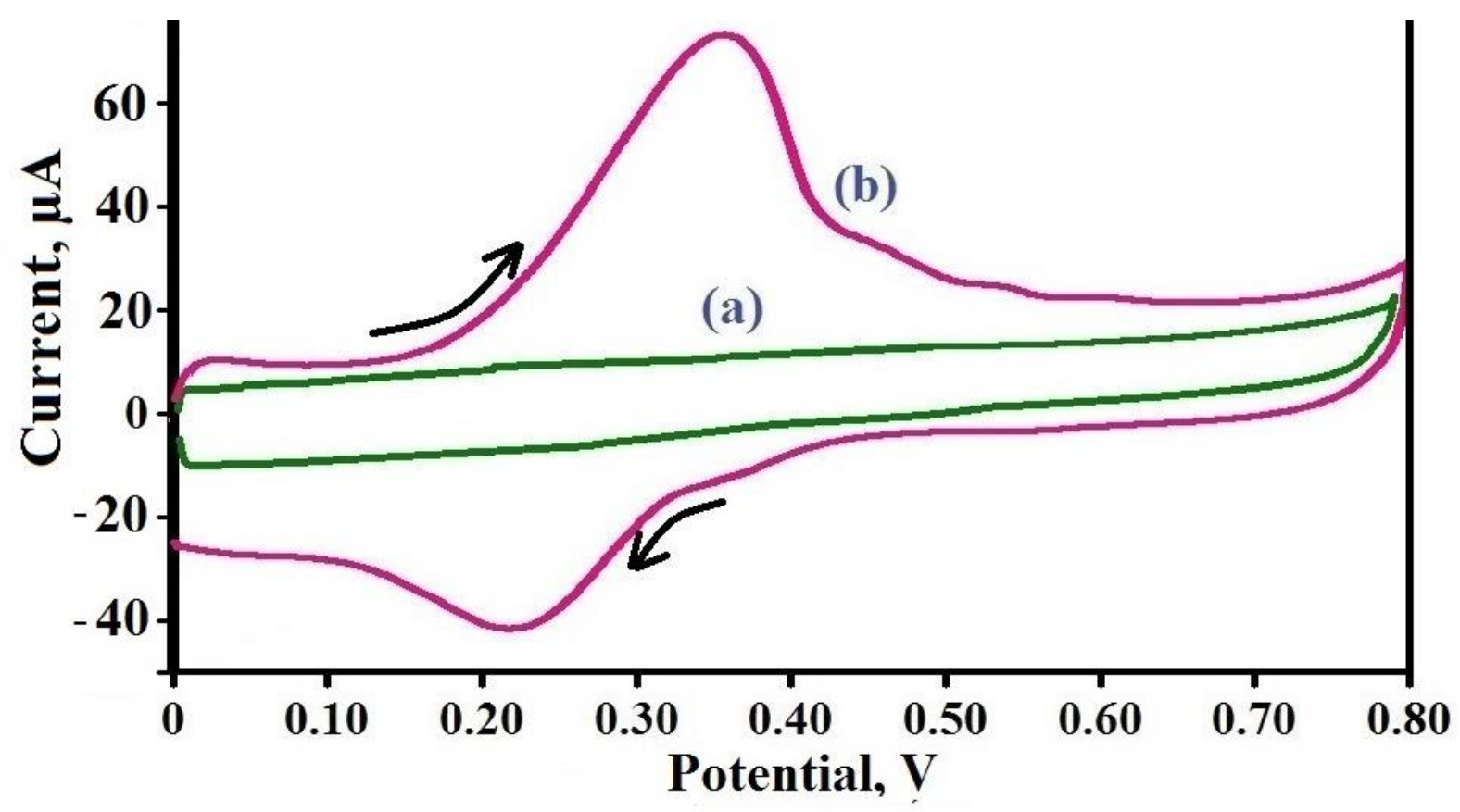

Figure 4. CVs of PMMCNTPE without PC (curve a) and with $10^{-4} \mathrm{MPC}$ (curve b) in $0.2 \mathrm{M} P B S$ of $\mathrm{pH} 7.5$, at the scan rate $0.1 \mathrm{~V} \mathrm{~s}^{-1}$. 


\section{Effect of $\mathrm{pH}$ variation}

The $\mathrm{pH}$ of the supporting electrolyte is one of the main experimental parameters affecting the voltammetric response of $\mathrm{PC}$ at PMMCNTPE. Therefore, an optimum $\mathrm{pH}$ is required to maximize the intensity of redox peak currents. Figure 5(a) illustrates voltammetric responses of PC in $0.2 \mathrm{M}$ PBS of $\mathrm{pH}$ varying from 6.5 to 8.0, at the scan rate $0.1 \mathrm{~V} \mathrm{~s}^{-1}$. As can be deduced from CVs in Figure 5(a), the current signal of PC at PMMCNTPE increases with elevating $\mathrm{pH}$ value from 6.5-7.5, and after that, the current signal decreases with further increase of $\mathrm{pH}$ value. This is clearly shown in Figure 5 (b) from the graphical plot of $I_{\text {pa. }} v s$. $\mathrm{pH}$. Thus, $\mathrm{pH} 7.5$ was selected as the optimum $\mathrm{pH}$ value for further experiments. In Figure $5(\mathrm{c})$, the graph of $E_{\mathrm{pa}}$ vs. $\mathrm{pH}$ is plotted, showing a linear relationship between the oxidation peak potential and $\mathrm{pH}$ value in the range 6.5 to 8.0. The displayed linear regression equation is:

$$
E_{\mathrm{pa}} / \mathrm{V}=0.0705-0.0453 \mathrm{pH}\left(\mathrm{R}^{2}=0.9968\right)
$$
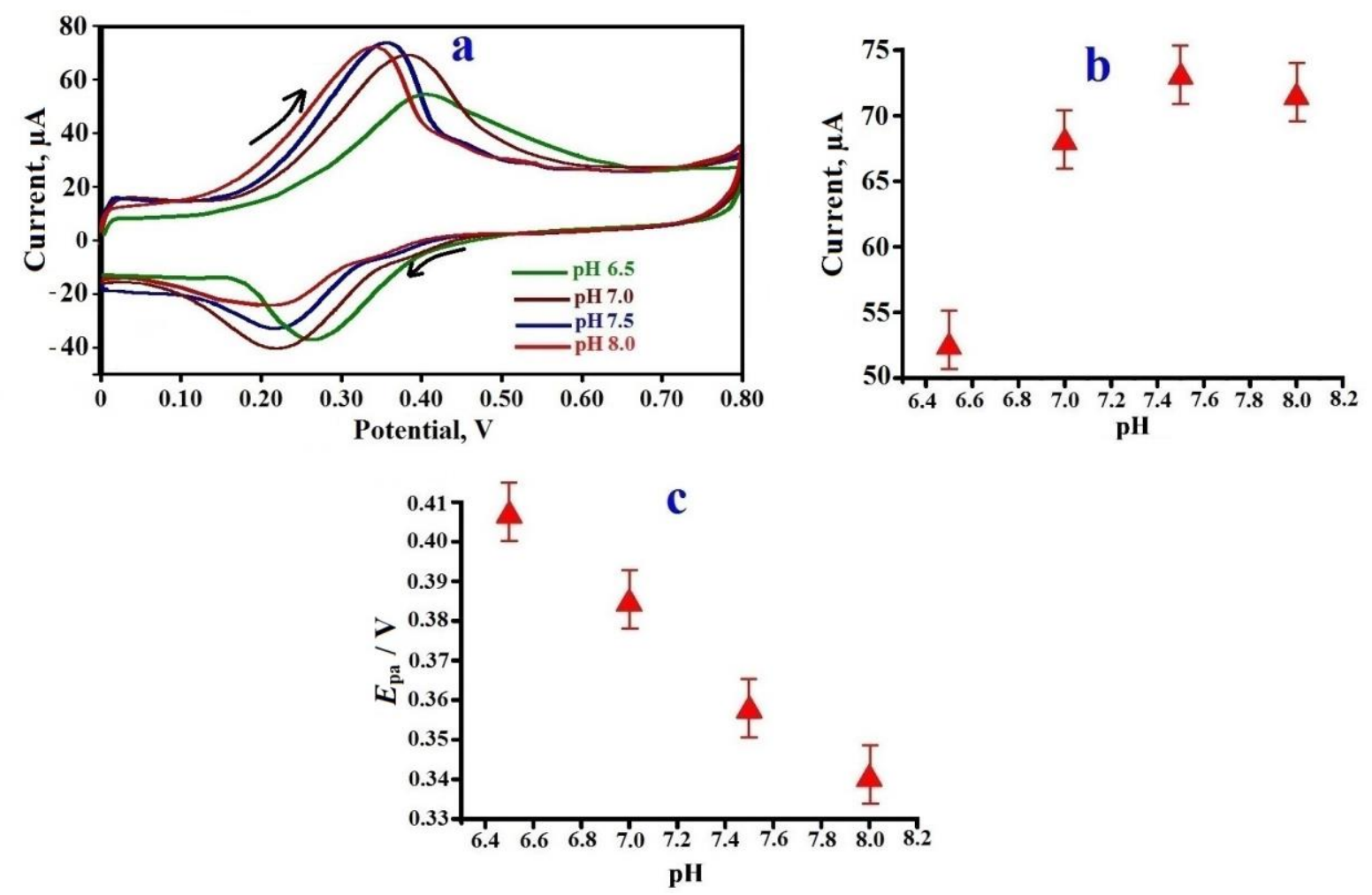

Figure 5: (a) CVs of $10^{-4} \mathrm{M} P C$ at PMMCNTPE in $0.2 \mathrm{M} \mathrm{PBS}$ at $\mathrm{pH}$ varying from 6.5-8.0, at the scan rate $0.1 \mathrm{Vs}^{-1}$, (b) $\mathrm{I}_{p a}$, vs. $\mathrm{pH}$ dependence, (c) $\mathrm{E}_{p a} v s$. $\mathrm{pH}$ dependence

\section{Impact of scan rate}

Figure 6(a) presents CVs of $10^{-4} \mathrm{M} \mathrm{PC}$ at PMMCNTPE in $0.2 \mathrm{M}$ PBS of $\mathrm{pH} 7.5$ at various scan rates (v) ranging from 0.1-0.3 $\mathrm{V} \mathrm{s}^{-1}$. The rise in the potential scan rate leads to successive increase in peak current value and at the same time, oxidation peak potential is shifted to more positive potentials. This can also be inferred from the graphical plot of $I_{\text {pa }}$ vs. square root of scan rate shown in Figure $6(b)$, where the linear regression equation is represented as

$$
I_{\mathrm{pa}} / \mu \mathrm{A}=0.3227+0.0351\left(v^{1 / 2}\right)\left(\mathrm{R}^{2}=0.9995\right)
$$

Linearity between $I_{\mathrm{pa}}$ and square root of $v$ indicates that the redox process of PC at the surface of PMMCNTPE is diffusion controlled [40-41]. The graphical plot of $\log /$ pa $v s$. $\log v$ was constructed and shown in Figure 6(c). Good linearity was obtained and the linear fitted equation is expressed as

$$
\log \left(I_{\mathrm{pa}} / \mu \mathrm{A}\right)=5.3634+0.6336 \log v\left(\mathrm{R}^{2}=0.9959\right)
$$


The obtained slope from the graph is 0.63 , which is very close to the speculative value 0.5 [42]. This suggests that the redox process of PC at PMMCNTPE is a diffusion-controlled process.
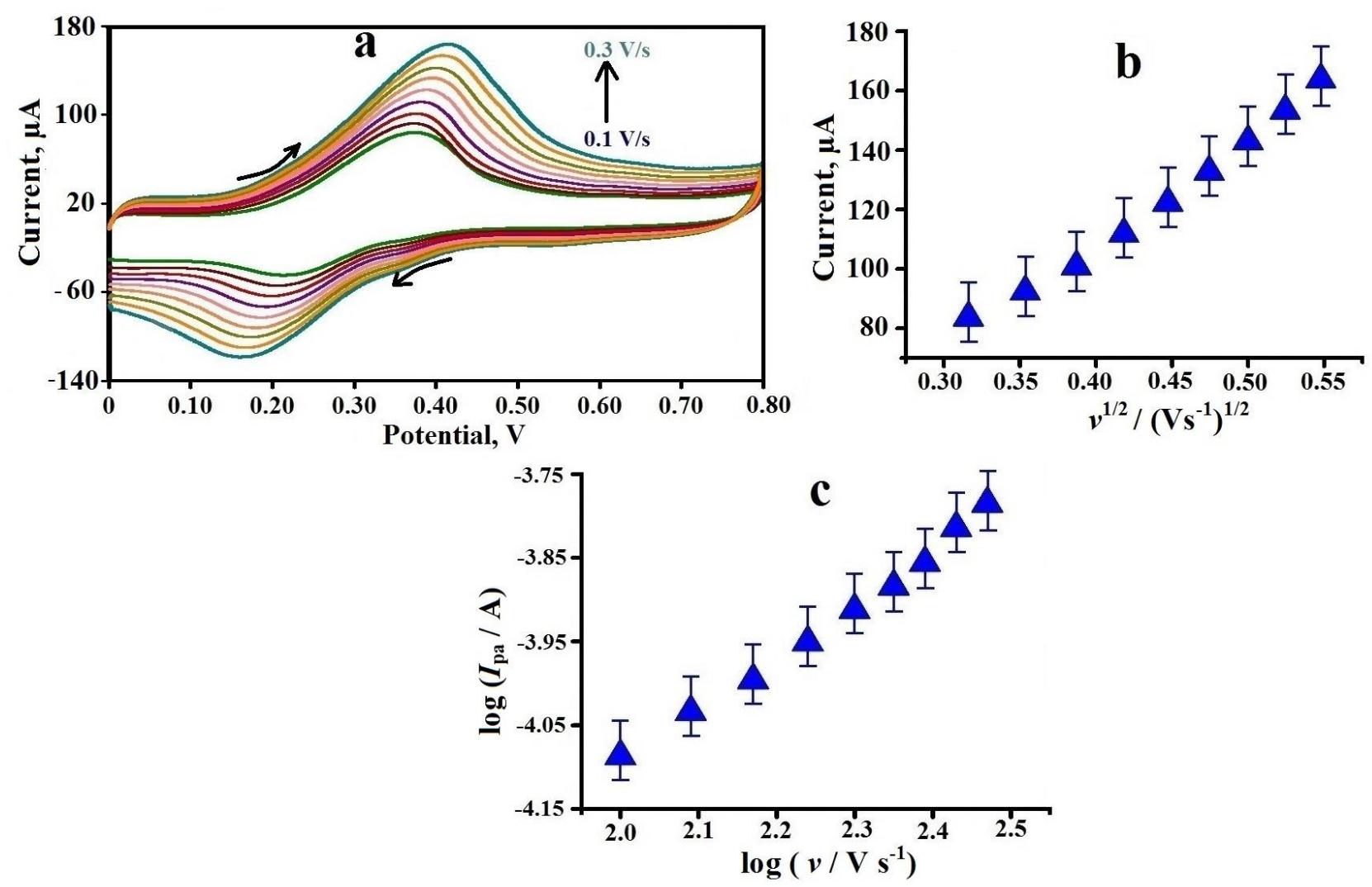

Figure 6: (a) CVs of $10^{-4} \mathrm{M} P C$ at PMMCNTPE in $0.2 \mathrm{M}$ PBS of $\mathrm{pH} 7.5$, recorded at different scan rates ranging from 0.1-0.3 $\mathrm{V} \mathrm{s}^{-1}$ (b) $\mathrm{I}_{p a} v \mathrm{Vs}$. square root of scan rate (c) log $\mathrm{I}_{p a} v \mathrm{vs}$ log $\mathrm{l}$ dependence

\section{Voltammetric determination of PC on PMMCNTPE}

The main aim of this study is to develop the sensing electrode based on PMMCNTPE to detect low PC concentrations. Therefore, electro-oxidation of PC at PMMCNTPE in 0.2 M PBS of pH 7.5 was carried out by varying its concentration in the range from $2 \times 10^{-6} \mathrm{M}-1.1 \times 10^{-4} \mathrm{M}$. Figure 7 displays the graphical plot of $I_{\text {pa }} v s$. concentration of PC, specifying that by increasing the concentration of PC peak current also increases, showing the linear relationship between $/ \mathrm{pa}$ and concentration of PC. The linearity is obtained in the range of $2.0 \times 10^{-6} \mathrm{M}-5.0 \times 10^{-5} \mathrm{M}$, and the linear fitted equation is expressed as

$$
I_{\mathrm{pa}} / \mu \mathrm{A}=0.3035+4.0305 \mathrm{M}\left(\mathrm{R}^{2}=0.9992\right)
$$

The limit of detection (LOD) and limit of quantification (LOQ) were calculated by using the equation $L O D=3 \times S / M$ and $L O Q=10 \times S / M$, respectively, where $S$ is the standard deviation of the blank and $\mathrm{M}$ is the slope of the calibration curve [43]. The calculated LOD and LOQ are $3.85 \times 10^{-8} \mathrm{M}$ and $1.28 \times 10^{-7} \mathrm{M}$, respectively. A comparison of linear ranges and LOD values for PC determination with those obtained for some other electrodes [44-51] is listed in Table 1 to assess the efficiency of the here fabricated sensor 


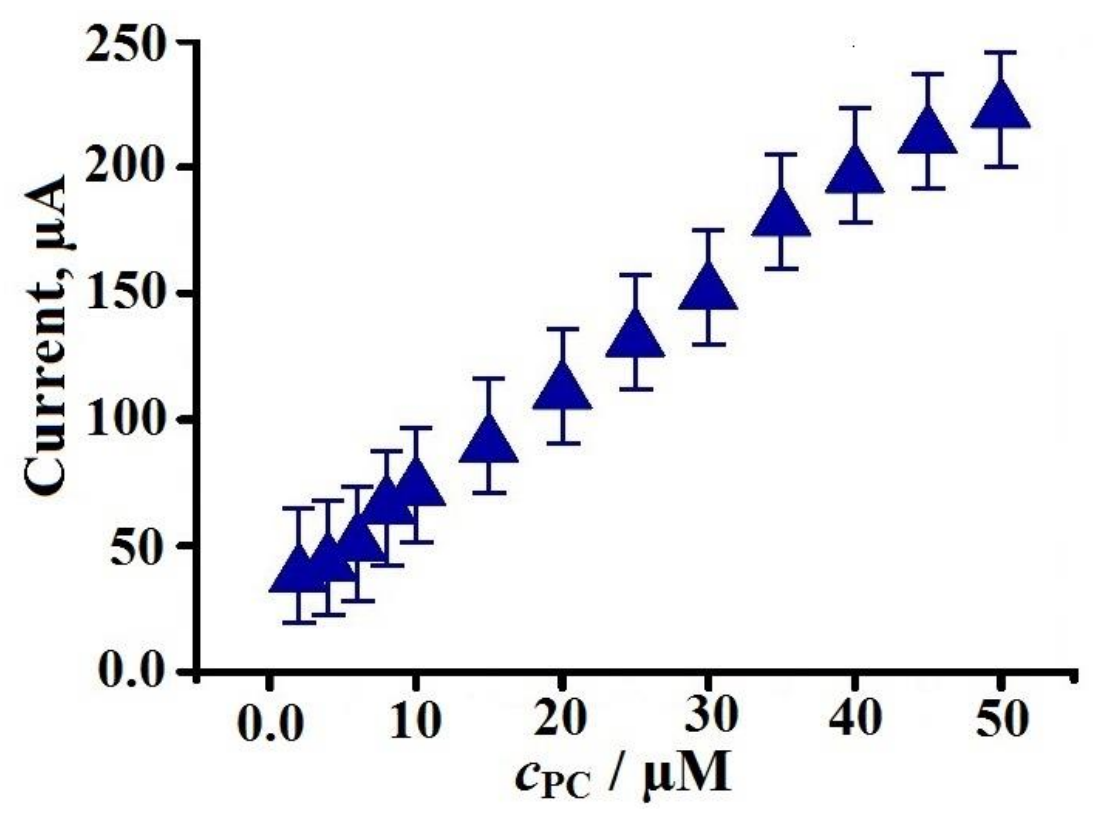

Figure 7. The graphical plot of $I_{p a} v s$. concentration of $P C$

Table 1. Comparison of linear ranges and detection limits for $P C$ at different electrodes

\begin{tabular}{|c|c|c|c|c|}
\hline Serial No. & Electrode & Linear working range of $\mathrm{PC}, \mu \mathrm{M}$ & Detection limit of $\mathrm{PC}, \mu \mathrm{M}$ & References \\
\hline 1 & AuNP-PGA/CNT & $8.3-140$ & 1.2 & [44] \\
\hline 2 & $\mathrm{tY} /$ nano- $\mathrm{TiO}_{2} / \mathrm{GCE}$ & $12-120$ & 2.0 & [45] \\
\hline 3 & PANI-MWCNT & $1.0-100$ & 0.25 & {$[46]$} \\
\hline 4 & PEDOT-GCE & $1.0-100$ & 0.40 & [47] \\
\hline 5 & CHCFE-CPE & $1.0-10$ & 0.46 & [48] \\
\hline 6 & BDDE & $50-83$ & 0.49 & [49] \\
\hline 7 & Ru-CCE & $1.99-31$ & 0.58 & {$[50]$} \\
\hline 8 & Ni-Al-HCF-GCE & $3.0-1500$ & 0.80 & {$[51]$} \\
\hline 9 & PMMCNTPE & $2.0-50$ & 0.38 & Present work \\
\hline
\end{tabular}

AuNP-PGA/CNT: glutamic acid and gold nanoparticles on a single-walled carbon nanotube film;

PAY: poly(acid yellow 9); GCE: glassy carbon electrode; PANI-MWCNT: polyaniline-multi-walled carbon nanotubes; PEDOT: poly(3,4-ethylenedioxythiophene); CHCFE-CPE: Cobalt hexacyano ferrate carbon paste electrode; BDDE: boron doped diamond electrode; Ru-CCE: arene-ruthenium (II) complex carbon ceramic electrode; Ni-Al-HCF: hexacyanoferate(III) intercalated Ni Al layered double hydroxide.

Repeatability, reproducibility and stability

The repeatability of PMMCNTPE was scrutinized by four repetitive measurements with the same electrode, resulting with the RSD of $2.2 \%$. The reproducibility of PMMCNTPE was inspected by four repetitive measurements with different PMMCNTPE electrodes, what-resulted in the RSD of $3.5 \%$. Both the repeatability and reproducibility exposed RSD less than $4 \%$, indicating thus good repeatability and reproducibility of the proposed sensor. The stability of the designed sensor was assessed by 30 successive potential cycles. The percentage degradation was calculated by using the following formula

Degradation, \% $=\left(I_{\mathrm{pn}} / I_{\mathrm{p} 1}\right) 100$

where $I_{\mathrm{pn}}$ and $I_{\mathrm{p} 1}$ are the last and first anodic peak current, respectively [52]. The calculated percentage degradation is $94 \%$. This suggests that the modified electrode retained its activity even after 30 cycles. Good stability, excellent reproducibility and acceptable repeatability confirm the excellent performance of the proposed sensor. 


\section{Voltammetric response of PC at PMMCNTPE by DPV technique}

The voltammetric response of PC at PMMCNTPE was also recorded via differential pulse voltammetry (DPV) technique. Figure 8 depicts differential pulse voltammograms (DPVs) of the electro-oxidation of $10^{-4} \mathrm{M} \mathrm{PC}$ in $0.2 \mathrm{M} \mathrm{PBS}$ of $\mathrm{pH} 7.5$ at the sweep rate $0.1 \mathrm{~V} \mathrm{~s}^{-1}$ on the surfaces of PMMCNTPE and BCNTPE. At the surface of the PMMCNTPE, an enhanced current sensitivity was observed for the electro-oxidation of PC, while for BCNTPE in identical conditions, inferior voltammetric response was obtained. The peak current of $71.9 \mu \mathrm{A}$ at peak potential of $0.268 \mathrm{~V}$ was obtained for the electrochemical oxidation of PC at PMMCNTPE. Thus, good electro-catalytic activity towards the electro-oxidation of PC at PMMCNTPE is confirmed via DPV approach too.

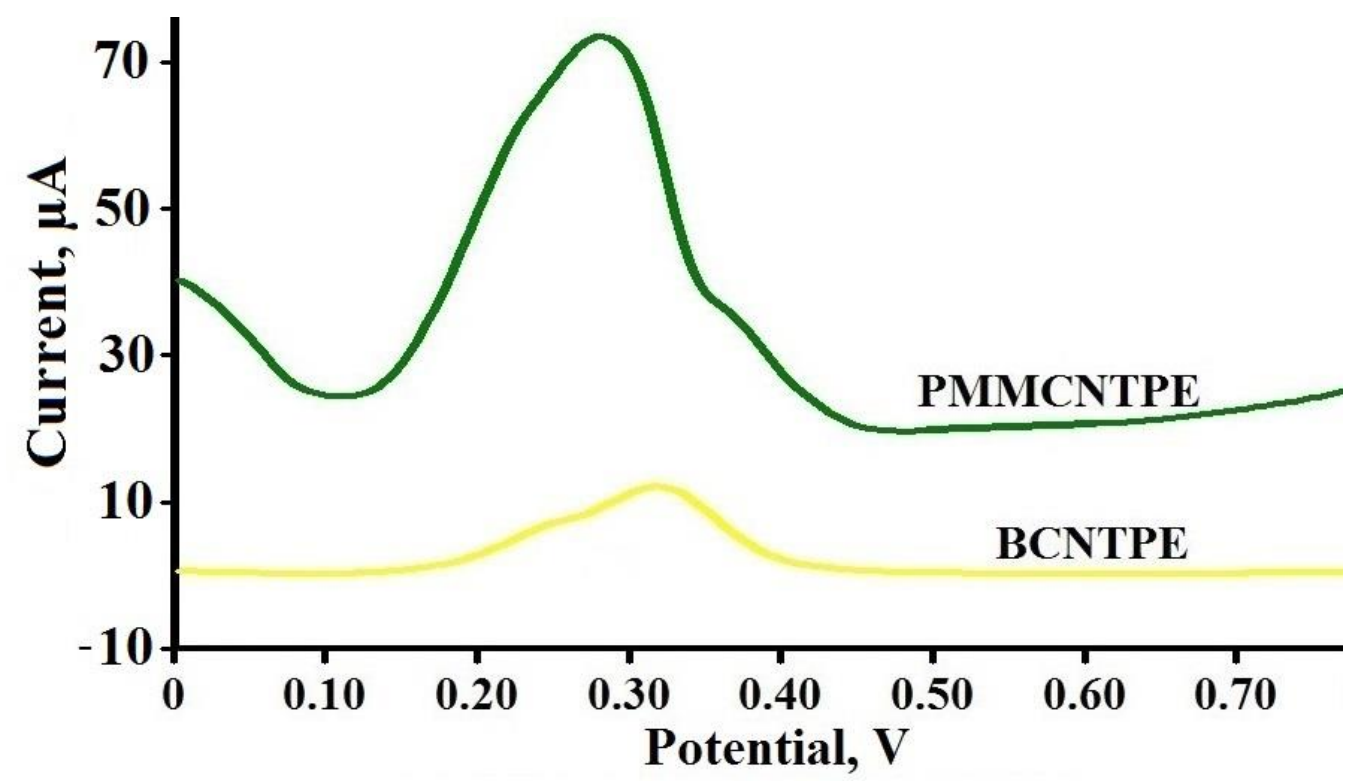

Figure 8. DPVs recorded for $10^{-4} \mathrm{M} P C$ at BCNTPE and PMMCNTPE in $0.2 \mathrm{M} P B S$ of $p H$ 7.5, at the sweep rate $0.1 \mathrm{Vs}^{-1}$.

\section{Interference study}

The selectivity of the designed PMMCNTPE sensor was examined by carrying out the interference study through CV and DPV methods. Folic acid (FA) and dopamine (DA) are commonly coexisting with PC in biological samples. Thus, the simultaneous detection of PC, FA, and DA was performed. Figure 9(a) shows CVs of PMMCNTPE in $0.2 \mathrm{M} \mathrm{PBS}$ of $\mathrm{pH} 7.5$ with simultaneous presence of PC $\left(10^{-4} \mathrm{M}\right), \mathrm{DA}\left(10^{-4} \mathrm{M}\right)$ and $\mathrm{FA}\left(10^{-4} \mathrm{M}\right)$. Figure $9(\mathrm{~b})$ shows $\mathrm{CV}$ s for the concentration of $\mathrm{PC}$ varied in the range of $10^{-4}-3.5 \times 10^{-4} \mathrm{M}$ and concentrations of DA and FA kept constant $\left(10^{-4} \mathrm{M}\right)$. In all cases, the scan rate $0.1 \mathrm{~V} \mathrm{~s}^{-1}$ was performed within the potential window $-0.2 \mathrm{~V}$ to $1.0 \mathrm{~V}$. Three wellseparated and sharp peaks for DA, PC, and FA were gained in CVs of Figures 9(a) and (b). Furthermore, by increase of $P C$ concentration from $10^{-4}$ to $3.5 \times 10^{-4} \mathrm{M}$, peak current of PC also increases, what can clearly be observed in Figure $9(b)$ and is also shown by plotting the graph of $I_{\mathrm{pa}}$ vs. concentration of PC in Figure 9(c). All these above-mentioned results suggest that good selectivity of the designed sensor has been achieved via CV technique.

Simultaneous detection of PC, DA, and FA was also performed by means of DPV technique. DPV of simultaneous detection of PC $\left(10^{-4} \mathrm{M}\right)$, DA $\left(10^{-4} \mathrm{M}\right)$ and FA $\left(10^{-4} \mathrm{M}\right)$ in $0.2 \mathrm{M}$ PBS of $\mathrm{pH} 7.5$ is displayed in Figure 10(a), where distinct peaks for DA, FA and particularly for PC can be observed. Figure 10 (b) depicts DPVs for the variation of PC concentration from $10^{-4}$ to $3.5 \times 10^{-4} \mathrm{M}$ without changing the concentration of DA and FA equal to $10^{-4} \mathrm{M}$ for each. The graphical plot of $I_{\text {pa }} v s$. concentration of PC shown in Figure 10(c) implies that for the increasing concentration of PC, peak 
current also increases. This approves that the fabricated sensor detects $P C$ in the presence of interference compounds DA and FA.
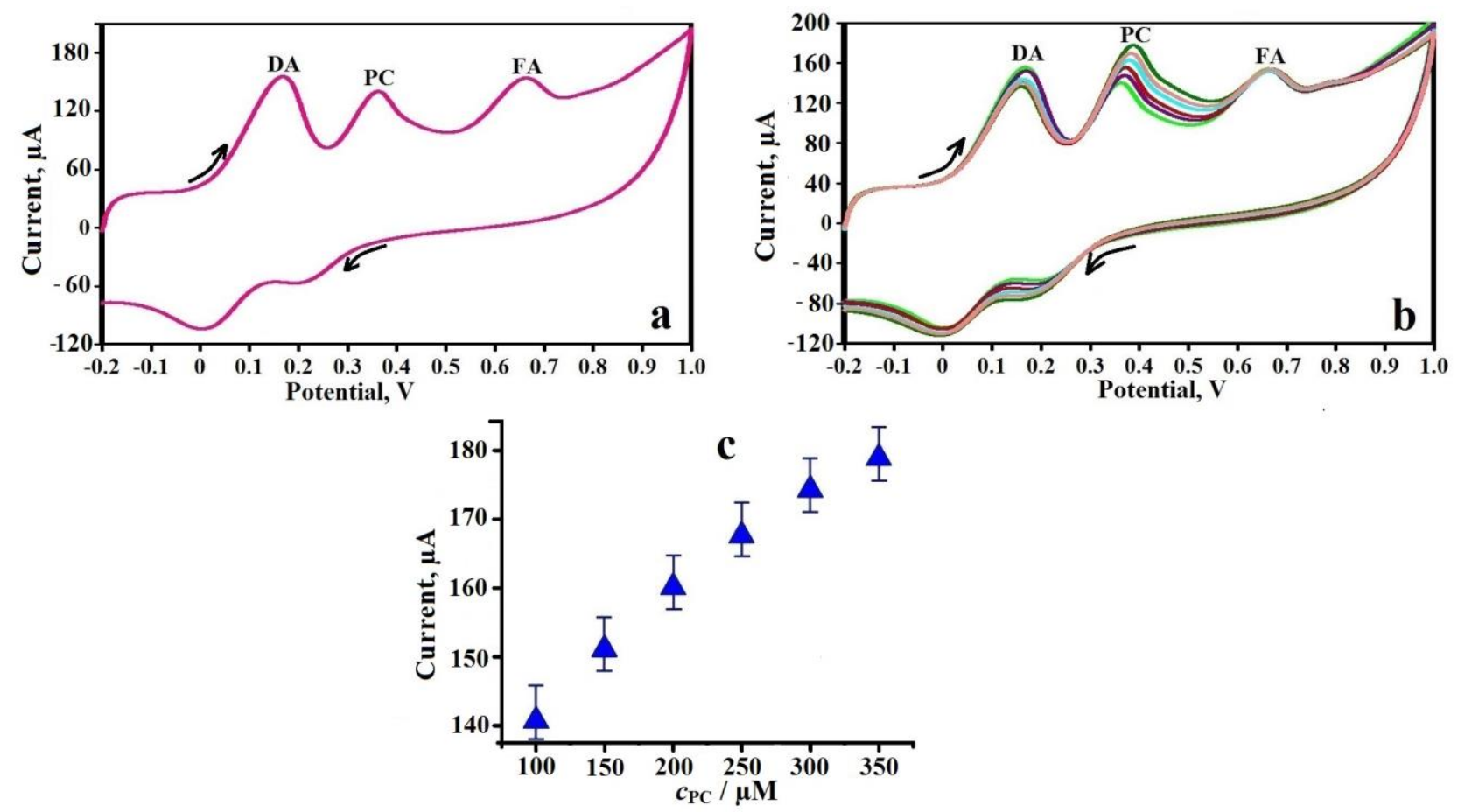

Figure 9. $\mathrm{CV}$ at PMMCNTPE in $0.2 \mathrm{M} P B S$ of $\mathrm{pH} 7.5$, recorded at the scan rate $0.1 \mathrm{Vs}^{-1}$ in presence of: (a) $P C\left(10^{-4} \mathrm{M}\right), D A\left(10^{-4} \mathrm{M}\right)$ and $F A\left(10^{-4} \mathrm{M}\right),(b) D A\left(10^{-4} \mathrm{M}\right), F A\left(10^{-4} \mathrm{M}\right)$, and $P C$ of varying concentration from $10^{-4}-3.5 \times 10^{-4} \mathrm{M}$, (c) $\mathrm{I}_{p a}$ vs. concentration of $P C$.
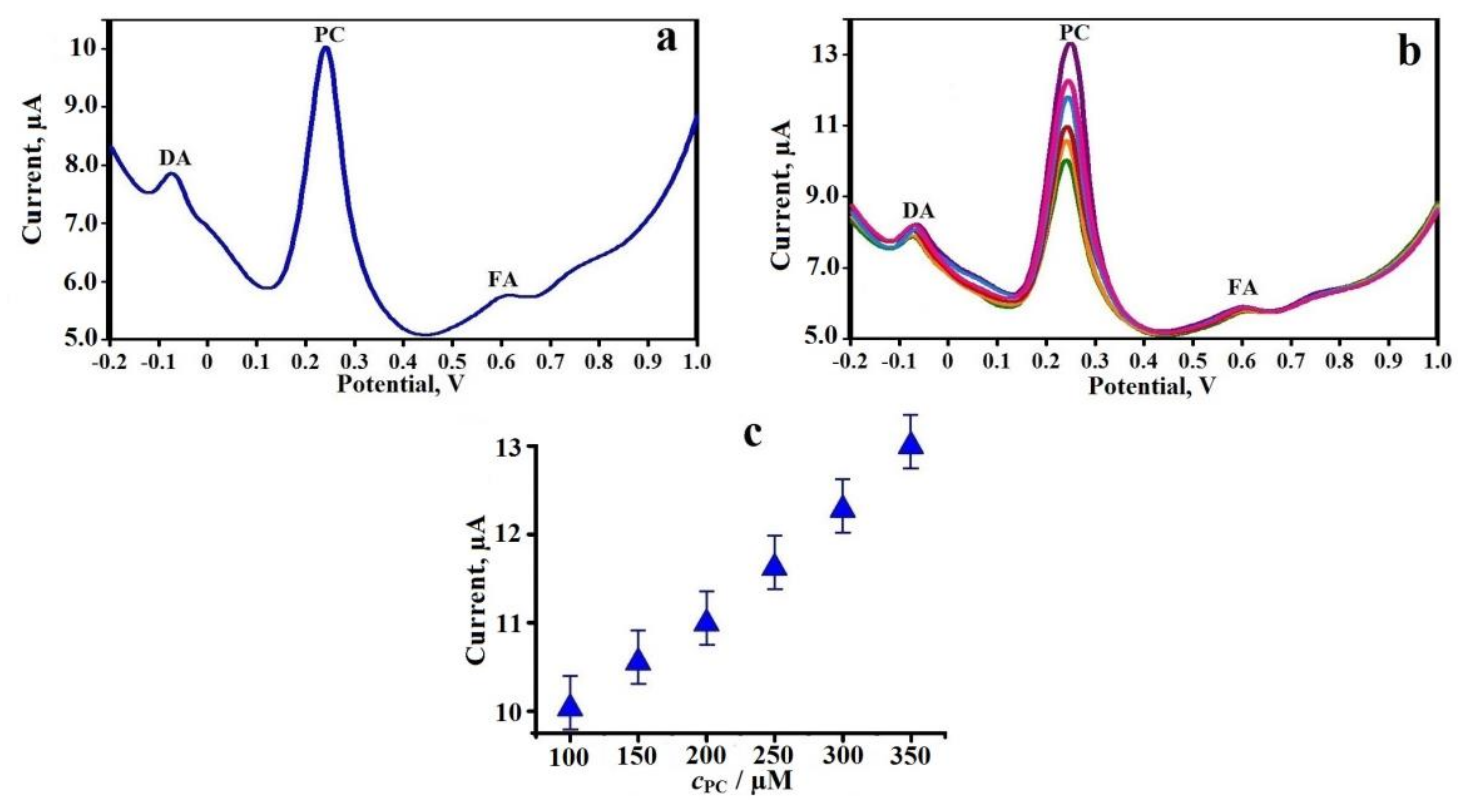

Figure 10. DPVs of PMMCNTPE in $0.2 \mathrm{M} P B S$ of $\mathrm{pH} 7.5$, recorded at the scan rate $0.1 \mathrm{~V} \mathrm{~s}^{-1}$ for simultaneous detection of $P C, D A$ and $F A$ at: (a) $P C\left(10^{-4} \mathrm{M}\right), D A\left(10^{-4} \mathrm{M}\right)$ and $F A\left(10^{-4} \mathrm{M}\right)(\mathrm{b}) D A\left(10^{-4} \mathrm{M}\right), F A\left(10^{-4} \mathrm{M}\right)$ and $P C$ varied from $10^{-4}-3.5 \times 10^{-4} \mathrm{M},(c)$ Graphical plot of $I_{p a}$ vs. concentration of $P C$

\section{Real sample analysis}

The workability of the constructed PMMCNTPE sensor for the analysis of PC was assessed by detecting PC in some pharmaceutical formulations, such as paracetamol and Dolo tablets that were procured from the local drugstore. The tablets were weighed and ground into a fine powder using 
the pestle in a mortar. Solutions were prepared from powdered tablets and analyzed by CV technique. The CVs were documented in $0.2 \mathrm{M} \mathrm{PBS}$ of $\mathrm{pH} 7.5$ at the sweep rate of $0.1 \mathrm{~V} \mathrm{~s}^{-1}$. A good recovery ranges from 95 to $103 \%$ was accomplished by the developed method.

\section{Conclusions}

In this study, PMMCNTPE was prepared as electrochemical sensor which could serve for a sensitive and selective determination of PC. The fabricated PMMCNTPE disclosed good electrocatalytic activity towards the oxidation of PC with CV and DPV techniques. The PMMCNTPE sensor boosted the analytical sensitivity of PC by yielding low detection limit of $3.8 \times 10^{-8} \mathrm{M}$. The sensor unveiled an excellent stability, repeatability, and reproducibility. In addition, the fabricated sensor was implemented to the simultaneous detection of PC, DA, and FA, showing significant selectivity. The sensing performance of the developed sensor was successfully applied for the determination of $P C$ in some pharmaceutical formulations. This implies that routine analysis of PC can be established following the proposed technique. This simple and quick method provides benefits like low cost, short analysis time and good detection limit.

Acknowledgements: We gratefully acknowledge the financial support from the VGST, Bangalore under Research Project. No. KSTePS/VGST-KFIST (L1)2016-2017/GRD-559/2017-18/126/333, 21/11/2017 and SC/ST Fellowship No. MU/SCT RF/CR17/2017-18, Mangalore University

\section{References}

[1] F. R. Lichtenberg, International Journal of Health Care Finance and Economics 5 (2005) 47-73.

[2] A. K. Wagner, J. D. Quick, D. Ross-Degnan, BMC Health Services Research 14 (2014) 1-6.

[3] M. A. Mallah, S. H. Sherazi, M. I. Bhanger, S. A. Mahesar, M. A. Bajeer, Spectrochimica Acta Part A 141 (2015) 64-70.

[4] H. Beitollahi, F. Garkani-Nejad, S. Tajik, M. R. Ganjali, Iranian Journal of Pharmaceutical Research 18 (2019) 80-90.

[5] R. N. Goyal, V. K. Gupta, M. Oyama, N. Bachheti, Electrochemistry Communications 7 (2005) 803-807.

[6] T. Skeika, M. Ferreira de Faria, N. Nagata, C. A. Pessoa, Journal of the Brazilian Chemical Society 19 (2008) 762-768.

[7] S.J. Richard Prabakar, S.S. Narayanan, Talanta 72 (2007) 1818-1827.

[8] A. U. Alam, Y. Qin, M. M. R. Howlader, N.-X. Hu, M. J. Deen, Sensors and Actuators B 254 (2018) 896909.

[9] S. F. Mbokou, M. Pontié, B. Razafimandimby, J. Bouchara, E. Njanja, I. Tonle Kenfack, Analytical and Bioanalytical Chemistry 408 (2016) 5895-5903

[10] R. T. Kachoosangi, G. G. Wildgoose, R. G. Compton, Analytica Chimica Acta 618 (2008) 54-60.

[11] A. M. Larson, J. Polson, R. J. Fontana, T. J. Davern, E. Lalani, L. S. Hynan, J. S. Reisch, F. V. Schiødt, G. Ostapowicz, A. O. Shakil, W. M. Lee, Hepatology 42 (2005) 1364-1372.

[12] M. Mazer, J. Perrone, Journal of Medical Toxicology 4 (2008) 2-6.

[13] N. T. Anh Thu, H. V. Duc, N. H. Phong, N. D. Cuong, N. T Vuong Hoan, D. Q. Khieu, Journal of Nanomaterials 2018 (2018) ID 7619419.

[14] B. D Blair, J. P. Crago, C. J. Hedman, R. D. Klaper, Chemosphere 93 (2013) 2116-2123.

[15] M. E. Bosch, A. J. Sánchez, F. S. Rojas, C. B. Ojeda, Journal of Pharmaceutical and Biomedical Analysis 42 (2006) 291-321.

[16] M. K. Srivastava, S. Ahmad, D. Singh, I. C. Shukla, Analyst 110 (1985) 735-737.

[17] K. G. Kumar, R. Letha, Journal of Pharmaceutical and Biomedical Analysis 15 (1997) 1725-1728.

[18] G. Burgot, F. Auffret, J.-L. Burgot, Analytica Chimica Acta 343 (1997) 125-128.

[19] W. Lohmann, U. Karst, Analytical and Bioanalytical Chemistry 386 (2006) 1701-1708.

[20] H.-G. Lou, H. Yuan, Z.-R. Ruan, B. Jiang, Journal of Chromatography B 878 (2010) 682-688.

[21] I. Baranowska, B. Kowalski, Water, Air and Soil Pollution 211 (2010) 417-425.

[22] G. M. Hadad, S. Emara, W. M. Mahmoud, Talanta 79 (2009) 1360-1367. 
[23] M. G. Gioia, P. Andreatta, S. Boschetti, R. Gatti, Journal of Pharmaceutical and Biomedical Analysis 48 (2008) 331-339.

[24] S. Zhao, W. Bai, H. Yuan, D. Xiao, Analytica Chimica Acta 559 (2006) 195-199.

[25] W. Ruengsitagoon, S. Liawruangrath, A. Townshend, Talanta 69 (2006) 976-983.

[26] Y.Z. Fang, D.J. Long, J.N. Ye, Analytica Chimica Acta 342 (1997) 13-21.

[27] Sirajuddin, A. R. Khaskheli, A. Shah, M. I. Bhanger, A. Niaz, S. Mahesar, Spectrochimica Acta Part A: Molecular and Bimolecular Spectroscopy 68 (2007) 747-751.

[28] N. Al-Zoubi, J. E. Koundourellis, S. Malamataris, Journal of Pharmaceutical and Biomedical Analysis 29 (2002) 459-467.

[29] D. Šatinský, I. Neto, P. Solich, H. Sklenárová, M. Conceição, B. S. M. Montenegro, A. N. Araújo, Journal of Separation Science 27 (2004) 529-536.

[30] M. Shalash, A. Salhin, B. Saad, I. A. Rahman, Journal of Liquid Chromatography and Related Technologies 36 (2013) 155-166.

[31] M. S. M. Quintino, K. Araki, H. E. Toma, L. Angnes, Electroanalysis 14 (2002) 1629-1634.

[32] H. Beitollahi, F. G. Nejad, Electroanalysis 28 (2016) 2237-2244.

[33] H. Beitollahi, J. B. Raoof, H. Karimi-Maleh, R. Hosseinzadeh, Journal of Solid State Electrochemistry 16 (2012) 1701-1707.

[34] H. Beitollahi, K. Movlaee, M. R. Ganjali, P. Norouzi, Journal of Electroanalytical Chemistry 799 (2017) 576-582.

[35] H. Beitollahi, S. Nekooei, M. Torkzadeh-Mahani, Talanta 188 (2018) 701-707.

[36] V. K. Gupta, T. A. Saleh, Environmental Science and Pollution Research 20 (2013) 2828-2843.

[37] K. Giribabu, Y. Haldorai, M. Rethinasabapathy, S.-C. Jang, R. Suresh, W.-S. Cho, Y.-K. Han, C. Roh, Y.-

S. Huh, V. Narayanan, Current Applied Physics 17 (2017) 1114-1119.

[38] C. Raril, J. G Manjunatha, Biomedical Journal of Science and Technical Research 9 (2018) 7149-7154.

[39] M. Baccarin, F. A. Santos, F. C. Vicentini, V. Zucolotto, B. C. Janegitz, O. Fatibello-Filho, Journal of Electroanalytical Chemistry 799 (2017) 436-443.

[40] N. Karikalan, R. Karthik, S.-M. Chen, M. Velmurugan, C. Karuppiah, Journal of Colloids and Interface Science 483 (2016) 109-117.

[41] T. T. Minh, N. H. Phong, H. V. Duc, D. Q. Khieu, Journal of Materials Science 53 (2018) 2453-2471.

[42] A. Wong, A. M. Santos, O. Fatibello-Filho, Diamonds and Related Materials 85 (2018) 68-73.

[43] M. M. Charithra, J. G. Manjunatha, Materials Science for Energy Technologies 2 (2019) 365-371.

[44] M.-P.N. Bui, C. A. Li, K. N. Han, X.-H. Pham, G.H. Seong, Sensors and Actuators B 174 (2012) 318-324.

[45] S. Ashok Kumar, C. Tang, S. Chen, Talanta 76 (2008) 997-1005.

[46] M. Li, L. Jing, Electrochimica Acta 52 (2007) 3250-3257.

[47] S. Mehretie, S. Admassie, T. Hunde, M. Tessema, T. Solomon, Talanta 85 (2011) 1376-1382.

[48] R. C. Saini, L. Gebresilassie, T. Hunde, M. Tirfu, R. Pal, International Journal of Chemistry and Pharmaceutial Sciences 4 (2016) 122-129.

[49] B. C. Lourenção, R. A. Medeiros, R. C. Rocha-Filho, L. H. Mazo, O. Fatibello-Filho, Talanta 78 (2009) 748-752.

[50] S. Machado, G. N. Calaça, J. P. da Silva, M. P. de Araujo, R. T. Boeré, C. A. Pessôa, K. Wohnrath, Journal of the Electrochemical Society 164 (2017) B314-B320.

[51] K. Asadpour-Zeynali, R. Amini, Electroanalysis 29 (2017) 635-642.

[52] J. G. Manjunatha, Sensing and Bio-Sensing Research 16 (2017) 79-84.

(C)2019 by the authors; licensee IAPC, Zagreb, Croatia. This article is an open-access article distributed under the terms and conditions of the Creative Commons Attribution license (http://creativecommons. org/licenses/by/4.0/) 